
\title{
$\begin{array}{ll}\text { Research Square } & \text { Preprints are preliminary reports that have not undergone peer review. } \\ \text { They should not be considered conclusive, used to inform clinical practice, } & \text { or referenced by the media as validated information. }\end{array}$
}

\section{Detection and Dynamics of Circulating Tumor Cells in Patients with High-Risk Prostate Cancer Treated with Radiotherapy and Hormones: A Prospective Phase II Study}

Almudena Zapatero ( $\sim$ almudena.zapatero@salud.madrid.org )

Hospital Universitario de La Princesa https://orcid.org/0000-0003-2930-2312

Antonio Gómez-Caamaño

Hospital Clinico Universitario de Santiago de Compostela

María Ángeles Cabeza Rodriguez

Hospital Universitario 12 de Octubre

Laura Muinelo-Romay

Hospital Clinico Universitario de Santiago de Compostela

Carmen Martin de Vidales

Hospital Universitario La Princesa

Alicia Abalo

Hospital Clinico Universitario de Santiago de Compostela

Patricia Calvo Crespo

Complejo Hospitalario Universitario de Santiago de Compostela

Luis León Mateos

Hospital Clinico Universitario de Santiago de Compostela

Carlos Olivier

Hospital Universitario La Princesa

Lorena Vega Piris

Hospital Universitario La Princesa

Research

Keywords: Prostate cancer, circulating tumor cells (CTCs), radiotherapy, androgen suppression, treatment outcome, prognostic factor

Posted Date: February 14th, 2020

DOI: https://doi.org/10.21203/rs.2.23584/v1 
License: (c) (i) This work is licensed under a Creative Commons Attribution 4.0 International License. Read Full License

Version of Record: A version of this preprint was published at Radiation Oncology on June 1st, 2020. See the published version at https://doi.org/10.1186/s13014-020-01577-5. 


\section{Abstract}

Background: Circulating tumor cells (CTCs) are an established prognostic marker in castration-resistant prostate cancer but have received little attention in localized high-risk disease. We studied the detection rate of CTCs in patients with high-risk prostate cancer before and after androgen deprivation therapy and radiotherapy to assess its value as a prognostic and monitoring marker.

Patients and Methods: We performed a prospective analysis of CTCs in the peripheral blood of 65 treatment-naïve patients with high-risk prostate cancer. EPCAM-positive CTCs were enumerated using the CELLSEARCH system at 4 timepoints. A cut off of $0 \mathrm{vs} \geq 1 \mathrm{CTC} / 7.5 \mathrm{ml}$ blood was defined as a threshold for negative versus positive CTCs status.

Results: CTCs were detected in 5/65 patients $(7.5 \%)$ at diagnosis, 8/62 (12.9\%) following neoadjuvant $A D$, and 11/59 (18.6\%) at the end of radiotherapy, with a median CTC count/7.5 $\mathrm{ml}$ of 1 (range, 1-136). Only 1 patient presented a positive CTC result 9 months after radiotherapy. Positive CTC status was not significantly associated with any clinicopathologic factors. However, a significant association was observed between conversion of CTCs and stages T3 $(P=0.044)$ and N1 $(P=0.002)$. Detection of CTCs was not significantly associated with overall survival $(P>0.40)$.

Conclusions: We found a low detection rate for CTCs. De novo positive CTC counts after treatment are probably due to a passive mechanism associated with destruction of the tumor. Further studies with larger samples and more accurate assessment methods are needed to determine the prognostic and therapeutic potential of CTC detection.

Trial registration: ClinicalTrials.gov ID: NCT01800058

\section{Background}

High-risk prostate cancer is a challenging disease. The combination of high-dose radiotherapy and androgen deprivation represents the standard of care and has yielded encouraging results (1). More recently, preliminary results with the addition of abiraterone acetate or docetaxel $(2,3)$ to luteinizing hormone-releasing hormone agonists point to an improved outcome in selected patients. However, given that some subgroups of patients with unfavorable prognostic factors do not respond as well to these treatments, it is necessary to identify improved biomarkers in order to identify patients who require a more aggressive approach. Growing evidence of the clinical importance of detecting circulating tumor cells (CTCs) in the peripheral blood of cancer patients indicates that this is a relevant prognostic and predictive biomarker after care $(4,5)$.

Counting CTCs using the CELLSEARCH assay (Menarini, Silicon Biosystems Inc., Bologna, Italy) was recently proven to be a reliable prognostic biomarker in metastatic castration-resistant prostate cancer (6-9). More recently, the results of 2 prospective trials with abiraterone and chemotherapy (10) showed that changes in CTCs as early as 4 weeks after treatment identified patients who were not benefiting from 
treatment, thus suggesting that the CTCs count could be an intermediate biomarker for overall survival in advanced metastatic prostate cancer.

These data contradict the limited available information in non-metastatic prostate cancer. The few studies that have examined the response of CTCs to radiotherapy or radical prostatectomy in patients with localized prostate cancer have reported conflicting results $(11,12)$. Consequently, we conducted a prospective multicenter phase II study to determine the proportion of patients with high-risk or locally advanced prostate cancer who presented CTCs in peripheral blood at diagnosis and to assess the association between this finding and clinically recognized prognostic factors. We also analyzed the patterns of change in CTCs following androgen deprivation and radiotherapy in order to assess its potential impact on clinical outcome. We hypothesized that the CTCs count could not only identify patients with a poorer prognosis, but also determine the degree of response to treatment (sensitivity to radiotherapy and hormone therapy) in patients with high-risk prostate cancer.

\section{Material And Methods}

Patients and treatment. The study population comprised 66 treatment-naïve patients with non-metastatic prostate cancer recruited from 3 Spanish teaching hospitals between 2014 and 2016. Of these, 65 were eligible for the CTCs analysis. Patients aged 18 years or older with histologically confirmed adenocarcinoma of the prostate and $\geq 1$ high-risk factors (prostate-specific antigen [PSA] $>20 \mathrm{ng} / \mathrm{ml}$, Gleason 8-10, stage T3-4), N0 or N1, a Karnofsky performance score of $\geq 70$, and a life expectancy of more than 5 years were eligible for inclusion. The study was approved by the independent review board at each participating center and conducted according to the provisions of the Declaration of Helsinki and the Good Clinical Practice Guidelines of the International Conference on Harmonization. Patients provided their written informed consent before participating in the study.

Patients received combined modality therapy comprising high-dose radiotherapy and hormone therapy. Radiotherapy was administered using 3-dimensional conformational radiation therapy (45 patients) or intensity-modulated radiation therapy (20 patients) at a median dose of $76.3 \mathrm{~Gy}$ (range, 74.8-79.2) and 81.7 Gy (range, 70.6-82-8), respectively. Hormone therapy consisted of 4 months of neoadjuvant and concomitant androgen deprivation followed by adjuvant androgen deprivation for a median of 26 (1736) months.

Procedures. Peripheral blood samples were collected prospectively and analyzed to detect CTCs at 4 timepoints: 1) baseline or before starting treatment (visit 1); 2) after neoadjuvant androgen deprivation and before radiotherapy (visit 2);3) at the end of radiotherapy (visit 3); and 4) 6-12 months after the end of radiotherapy in those patients with 0 CTCs in the first determination and conversion to positive CTCs in the following determinations (visit 4). One tube $(7.5 \mathrm{~mL})$ of peripheral blood was obtained from each patient at each sampling point. We used the CELLSEARCH assay (Menarini, Silicon Biosystems Inc., Bologna, Italy), which is the only CTCs detection method approved by the United States Food and Drug Administration. Therefore, peripheral blood was analyzed using the CELLSEARCH Circulating Tumor Cell 
kit at the Liquid Biopsy Analysis Unit of the Health Research Institute of Santiago de Compostela. The system immunoisolated cells that were positive for epithelial cell adhesion molecule (EpCAM). Enriched cells were then labelled with phycoerythrin-conjugated anticytokeratin antibodies, allophycocyaninconjugated anti-CD45 antibodies, and 4,6-diamino-2-phenylindole to identify the nucleus. Digital images of the 3 different fluorescent dyes were acquired using the CELLTRACKS Analyzer and a 12-bit camera. The images were reviewed by trained operators in order to determine the CTCs count (Fig. 1). Round-oval, $\mathrm{DAPI}^{+}, \mathrm{CD}^{-} 5^{-}$, and $\mathrm{CK}^{+}$cells were considered CTCs.

Statistical methods. The frequency of expression of CTCs was estimated with its $95 \%$ confidence interval (Cl). Initially a cutoff point of $\geq 3 \mathrm{CTCs} / 7.5 \mathrm{~mL}$ of blood was taken as the reference baseline. Because of the low CTCs count observed and for statistical purposes, we empirically established a cut-off of $0 \mathrm{vs} \geq 1$ CTCs $/ 7.5 \mathrm{~mL}$ blood as the thresholds between negative and positive CTCs status. The association between the presence and development of CTCs over time and well-known clinicopathological features was assessed using the $\chi^{2}$ test or Fisher exact test. Overall survival, metastasis-free survival, and biochemical failure-free survival were estimated using the Kaplan-Meier method. The curves were compared using the log-rank test. All events were determined from the date of diagnosis to relapse, progression, or date of last follow-up visit. Cox regression models were constructed to estimate the hazard ratio and $95 \% \mathrm{Cl}$ as a measure of the effect and were adjusted for potential confounding variables $(P \leq 0.20)$. All hypothesis tests were performed using 2-tailed alternatives. Statistical significance was set at $\mathrm{P}<0.05$.

\section{Results}

The initial study sample comprised 66 high-risk patients, of whom 65 were evaluable for the analysis (1 patient was lost to follow-up before completing the CTCs study). The median age was 71 years (range, 53-79), and the median pretreatment PSA value was $12.6 \mathrm{ng} / \mathrm{mL}$ (range, 3.2-68.7). The Gleason score was $\geq 8$ in 28 patients, and 48 patients were in clinical stage T3. The median (IQR) follow-up was 55 (2364) months. Patient and treatment characteristics are summarized in Table 1.

The median CTCs count/7.5 mL at all of the time points was 1 (1-136). The changing pattern of detection over time is summarized in Table 2 and Fig. 2. At diagnosis (visit 1), CTCs were detected in only 5/65 patients (7.5\%). Of these, 3 became negative at visit 2 (following neoadjuvant androgen deprivation), and the remaining 2 patients became negative following radiotherapy (visit 3). At visit 2, CTCs were analyzed in 62 patients ( 3 patients did not complete the analysis), and de novo CTCs positivity was detected in 6 patients whose values became negative at visits 3 and 4 . We also observed de novo CTCs positivity at visit 3 (end of radiotherapy) in 8 patients. Only 1 patient presented positive CTCs results 9 months after radiotherapy.

Positive CTCs status (at any timepoint) was not significantly associated with clinical and pathologic factors (patient age, pre-treatment PSA, T stage, N stage, Gleason score, and number of positive cores). Similarly, we did not find an association between positive CTCs status and the presence of secondary 
tumors (Table 3). However, when we analyzed the variation pattern of positive CTCs results following treatment, we observed a significant association between CTCs conversion and stages T3 $(P=0.044)$ and N1 $(P=0.002)$.

Only 1 patient experienced biochemical relapse and metastatic disease (at 31 months) and is currently alive (no positive CTCs at any timepoint). Six patients died, none of them from prostate cancer. Detection of CTCs at diagnosis and following treatment was not significantly associated with overall survival $(P=0.40)$.

\section{Discussion}

The main objective of the present study was to assess the viability of detecting CTCs in non-metastatic high-risk prostate cancer patients. Our findings revealed a low count and incidence of CTCs. Only 5 out of 65 patients $(7.5 \%)$ harbored CTCs at diagnosis, that is, at the bottom range of the detection rates of other studies. The few published reports using the CELLSEARCH system in patients with localized prostate cancer showed positivity rates of $5-27 \%(13-15)$. These studies were carried out in patients treated predominantly with radical prostatectomy or brachytherapy and included early stages of prostate cancer. In an attempt to improve the CTCs detection rate, we focused the design of the study on including only patients with locally advanced, high-risk disease (13 patients had N1 disease and 30 patients had 2 or more risk factors). To our knowledge, this is the first prospective study performed in this subgroup of patients treated homogeneously with high-dose radiotherapy plus androgen deprivation and with repeated CTCs determinations at predetermined intervals to monitor treatment response.

The many methods used to detect CTCs range from real-time polymerase chain reaction to cell sizebased separation or immunomagnetic beads conjugated with anti-EpCAM antibodies (16-19), each of which is subject to intrinsic limitations, including reproducibility. For metastatic prostate cancer, the CELLSEARCH system was shown to provide prognostic information in several large clinical trials $(7,8,20$, 21). Nevertheless, in localized prostate cancer, the CELLSEARCH methodology is now believed to underestimate the actual number of CTCs, perhaps owing to fragmentation of conventional CTCs and the inability to detect the less epithelial CTCs (13). Data from recent studies have shown that EpCAM-based enrichment alone could not detect all CTCs subpopulations (22).

Several attempts have been made to overcome this limitation. Theil et al. (23) used a new system, the CellCollector to isolate in vivo CTCs in patients with different stages of prostate cancer and found more frequent detection of CTCs than with the CELLSEARCH system. Kuske et al. (24) also reported improved detection of CTCs in nonmetastatic prostate cancer patients by combining 3 independent CTCs assays: the CELLSEARCH system, CellCollector, and EPISPOT (an EPCAM-independent enrichment method). Peripheral blood samples were screened for CTCs before radical prostatectomy in 86 high-risk prostate cancer patients and 3 months after radical prostatectomy in 52 patients. The cumulative positivity rate of all 3 CTCs assays was $81.3 \%$ (87/107), with 21.5 (23/107) of patients harboring $\geq 5$ CTCs per blood sample. The authors hypothesize that the correlation observed with established risk factors and the 
persistence of CTCs 3 months after surgery could suggest the potential clinical relevance of CTCs as markers of minimal residual disease in prostate cancer.

The second objective of the present study was to analyze whether the variation in the CTCs count at predetermined intervals during the treatment regimen would predict outcome and enable a real-time response. We expected a decline in the numbers of CTCs following treatment. Unpredictably, an increasing and transient CTCs count was detected de novo after androgen deprivation and radiotherapy. The CTCs detection rate was $7.5 \%$ at diagnosis, which increased to $12.9 \%$ following neoadjuvant androgen deprivation and $18.6 \%$ at the end of radiotherapy before decreasing again to $7.5 \%$ at 9 months after the end of radiotherapy. When we investigated this changing pattern of CTCs positivization more specifically, we observed a significant association with locally advanced disease (T3-4 stage, $p=0.044$; and N1 stage, $p=0.002$ ). Although we do not have a clear explanation for this finding, we believe that it could be due to a passive mechanism associated with the destruction of the tumor. A further analysis with longer follow-up is required to clearly determine the relevance of CTCs positivation during the treatment.

Importantly, other authors have reported similar findings. Stott et al. (25) observed that of 11 patients with preoperative CTCs counts below the cutoff, 4 had transient elevations in CTCs during the follow-up period. Tsumura et al. (12) evaluated whether prostate brachytherapy procedures had a potential risk for hematogenous spillage of prostate cancer cells in 59 patients using the CELLSEARCH system. They detected CTCs from samples immediately after the brachytherapy procedure in 7 patients (intraoperative CTCs detection rates were significantly higher than preoperative ones). However, the authors did not repeat the CTCs analysis during follow-up to evaluate whether those CTCs could actually survive and proliferate at distant sites.

We were unable to show a significant association between positive CTCs status at diagnosis and known clinical and histologic prognostic factors. This lack of correlation has been extensively observed in studies carried out in localized prostate cancer $(11,16,25)$. The small sample size and the low CTCs detection rate might limit the weight of these results.

In one of the longest prospective series (152 patients analysed using the CELLSEARCH platform), Meyer et al. (26) did not observe a significant relationship with PSA, Gleason score, or pT stage. The CTCs detection rate in their series was only $11 \%$. Pal et al. (27) used a modified isolation procedure on the CELLSEARCH platform in 35 patients with high-risk, localized prostate cancer. With a CTCs detection rate of $49 \%$ prior to surgery, they did not observe any correlation between the presence of CTCs and clinicopathological prognostic features. Conversely, Kuske et al. (24) used the EPISPOT method before radical prostatectomy and found a significant association between CTCs and PSA and clinical T stage. The detection rate with EPISPOT was 58.7\%. However, they failed to show any clinical correlation with the other assays (the CELLSEARCH system and the in vivo CellCollector).

Only 1 patient in our series experienced biochemical and distant failure, and 6 patients have since died, none of them from prostate cancer. Again, we did not observe any association between CTCs count and 
overall survival. Although some authors report a trend towards shorter recurrence times (28), no studies to date have proved the predictive value of CTCs in disease-free or overall survival.

Our study is subject to the limitations inherent to an observational feasibility study, namely, the small sample size and short follow-up. The main strengths are its prospective design with pre-established CTCs determinations at predetermined intervals to monitor treatment response.

\section{Conclusion}

In conclusion, the data obtained from this study showed a low detection rate for CTCs in patients with high-risk prostate cancer. The finding of de novo positive CTC counts after androgen deprivation and radiotherapy (mostly with very low levels and not maintained over time) may be due to a passive mechanism associated with destruction of the tumor. Further studies with larger samples and a more acute assessment method are needed to determine the potential prognostic and therapeutic value of detection of CTCs in nonmetastatic prostate cancer.

\section{Abbreviations}

$\mathrm{Cl}$

Confidence interval

CTCS

Circulating tumor cells

EpCAM

Epithelial cell adhesion molecule

Gy

Gray

IQR

Interquartil Range

PSA

prostate-specific antigen

\section{Declarations}

\section{Consent for publication}

Not applicable

\section{Availability of data and materials' statement}

The datasets used and/or analyzed during the current study are available from the corresponding author on reasonable request. 


\section{Funding - Financial Support}

Funded by a grant from Janssen- Pharmaceuticals, number: 212082PCR4005

\section{Authors' Contributions}

AZ was the sponsor and chief investigator. AZ developed the protocol and wrote the report. LMR coordinated the study. LVP did the statistical analysis. All the investigators enrolled the patients, did the literature search, and were involved in the interpretation of data and the review of the report. All investigators approved the final version of the report for publication

\section{Acknowledgements}

We thank Thomas O'Boyle for his editorial assistance

\section{Authors' information}

Not applicable

\section{References}

1. Bolla M, Maingon P, Carrie C, Villa S, Kitsios P, Poortmans $P$, et al. Short Androgen Suppression and Radiation Dose Escalation for Intermediate- and High-Risk Localized Prostate Cancer: Results of EORTC Trial 22991. J Clin Oncol 2016;34(15):1748-56.

2. James ND, de Bono JS, Spears MR, Clarke NW, Mason MD, Dearnaley DP, et al. Abiraterone for Prostate Cancer Not Previously Treated with Hormone Therapy. N Engl J Med 2017;337(4):338-51.

3. James ND, Sydes MR, Clarke NW, Mason MD, Dearnaley DP, Spears MR, et al. Addition of docetaxel, zoledronic acid, or both to first-line long-term hormone therapy in prostate cancer (STAMPEDE): survival results from an adaptive, multiarm, multistage, platform randomised controlled trial. Lancet 2016;387:1163-77.

4. Fehm T, Sagalowsky A, Clifford E, Beitsch P, Saboorian H, Euhus D, et al. Cytogenetic evidence that circulating epithelial cells in patients with carcinoma are malignant. Clin Cancer Res 2002;8:207384.

5. Danila DC, Heller G, Gignac GA, Gonzalez-Espinoza R, Anand A, Tanaka E, et al. Circulating tumor cell number and prognosis in progressive castration-resistant prostate cancer. Clin Cancer Res 2007;13(23):7053-7.

6. de Bono JS, Scher HI, Montgomery RB, Parker C, Miller MC, Tissing H, et al. Circulating tumor cells predict survival benefit from treatment in metastatic castration-resistant prostate cancer. Clin Cancer Res 2008;14(19):6302-9.

7. Olmos D, Arkenau H, Ang JE, Ledaki I, Attard G, Carden CP, et al. Circulating tumour cell (CTC) counts as intermediate end points in castration-resistant prostate cancer (CRPC): a single-centre experience. 
Ann Oncol 2009;20(1):27-33.

8. Scher HI, Jia X, de Bono JS, Fleisher M, Pienta KJ, Raghavan D, et al. Circulating tumour cells as prognostic markers in progressive, castration-resistant prostate cancer: a reanalysis of IMMC38 trial data. Lancet Oncol 2009;10(3):233-9.

9. Heller G, McCormack R, Kheoh T, Molina A, Smith MR, Dreicer R, et al. Circulating Tumor Cell Number as a Response Measure of Prolonged Survival for Metastatic Castration-Resistant Prostate Cancer: A Comparison With Prostate-Specific Antigen Across Five Randomized Phase III Clinical Trials. J Clin Oncol 2018;36(6):572-80.

10. Lorente D, Olmos D, Mateo J, Bianchini D, Seed G, Fleisher M, et al. Decline in Circulating Tumor Cell Count and Treatment Outcome in Advanced Prostate Cancer. Eur Urol 2016;70(6):985-92.

11. Chalfin HJ, Glavaris SA, Malihi PD, Sperger JM, Gorin MA, Lu C, et al. Prostate Cancer Disseminated Tumor Cells are Rarely Detected in the Bone Marrow of Patients with Localized Disease Undergoing Radical Prostatectomy across Multiple Rare Cell Detection Platforms. J Urol 2018;199(6):14941501.

12. Tsumura H, Satoh T, Ishiyama H, Tabata K, Takenaka K, Sekiguchi A, et al. Perioperative Search for Circulating Tumor Cells in Patients Undergoing Prostate Brachytherapy for Clinically Nonmetastatic Prostate Cancer. Int J Mol Sci 2017;18(1):pii: E128.

13. Davis JW, Nakanishi H, Kumar VS, Bhadkamkar VA, McCormack R, Fritsche HA, et al. Circulating tumor cells in peripheral blood samples from patients with increased serum prostate specific antigen: initial results in early prostate cancer. J Urol 2008;179:2187-91.

14. Thalgott $M$, Rack $B$, Horn $T$, Heck MM, Eiber $M$, Kübler $H$, et al. Detection of Circulating Tumor Cells in Locally Advanced High-risk Prostate Cancer During Neoadjuvant Chemotherapy and Radical Prostatectomy. Anticancer Res 2015;35(10):5679-85.

15. Loh J, Jovanovic L, Lehman M, Capp A, Pryor D, Harris M, et al. Circulating tumor cell detection in high-risk non-metastatic prostate cancer. J Cancer Res Clin Oncol 2014;140(12):2157-62.

16. Gewanter RM, Katz AE, Olsson CA, Benson MC, Singh A, Schiff PB, et al. RT-PCR for PSA as a prognostic factor for patients with clinically localized prostate cancer treated with radiotherapy. Urology 2003;61(5):967-71.

17. Panteleakou Z, Lembessis P, Sourla A, Pissimissis N, Polyzos A, Deliveliotis C, et al. Detection of circulating tumor cells in prostate cancer patients: methodological pitfalls and clinical relevance. $\mathrm{Mol}$ Med 2009;15(3-4):101-14.

18. Miyamoto DT, Lee RJ. Cell-free and circulating tumor cell-based biomarkers in men with metastatic prostate cancer: Tools for real-time precision medicine? Urol Oncol 2016;34(11):490-501.

19. Gorin MA, Verdone JE, Van der Toom E, Bivalacqua TJ, Allaf ME, Pienta KJ. Circulating tumour cells as biomarkers of prostate, bladder, and kidney cancer. Nat Rev Urol 2017;14(2):90-7.

20. Goldkorn A, Ely B, Quinn DI, Tangen CM, Fink LM, Xu T, et al. Circulating tumor cell counts are prognostic of overall survival in SWOG S0421: a phase III trial of docetaxel with or without atrasentan for metastatic castration-resistant prostate cancer. J Clin Oncol 2014;32(11):1136-42. 
21. Zheng Y, Zhang C, Wu J, Cheng G, Yang H, Hua L, et al. Prognostic Value of Circulating Tumor Cells in Castration Resistant Prostate Cancer: A Meta-analysis. Urol J 2016;Vol 13(6):2881-8.

22. Schneck H, Gierke B, Uppenkamp F, Behrens B, Niederacher D, Stoecklein NH, et al. EpCAMIndependent Enrichment of Circulating Tumor Cells in Metastatic Breast Cancer. PLoS One 2015;10(12):e0144535.

23. Theil G, Fischer K, Weber E, Medek R, Hoda R, Lücke K, et al. The Use of a New CellCollector to Isolate Circulating Tumor Cells from the Blood of Patients with Different Stages of Prostate Cancer and Clinical Outcomes - A Proof-of-Concept Study. PLoS One 2016;11(8):e0158354.

24. Kuske A, Gorges TM, Tennstedt P, Tiebel AK, Pompe R, Preißer F, et al. Improved detection of circulating tumor cells in non-metastatic high-risk prostate cancer patients. Sci Rep 2016;6:39736.

25. Stott SL, Lee RJ, Nagrath S, Yu M, Miyamoto DT, Ulkus L, et al. Isolation and characterization of circulating tumor cells from patients with localized and metastatic prostate cancer. Sci Trans/ Med 2010;Mar 31; 2(25):25ra23.

26. Meyer CP, Pantel K, Tennstedt P, Stroelin P, Schlomm T, Heinzer H, et al. Limited prognostic value of preoperative circulating tumor cells for early biochemical recurrence in patients with localized prostate cancer. Urol Oncol 2016 May;34(5):235.e11-6.

27. Pal SK, He M, Wilson T, Liu X, Zhang K, Carmichael C, et al. Detection and phenotyping of circulating tumor cells in high-risk localized prostate cancer. Clin Genitourin Cancer 2015 April;13(2):130-6.

28. Friedlander TW, Welty C, Anantharaman A, Schonhoft JD, Jendrisak A, Lee J, et al. Identification and Characterization of Circulating Tumor Cells in Men Who Have Undergone Prostatectomy for Clinically Localized, High Risk Prostate Cancer. J Urol 2019;202:732-41.

\section{Tables}

Table 1. Summary of patient and treatment characteristics 


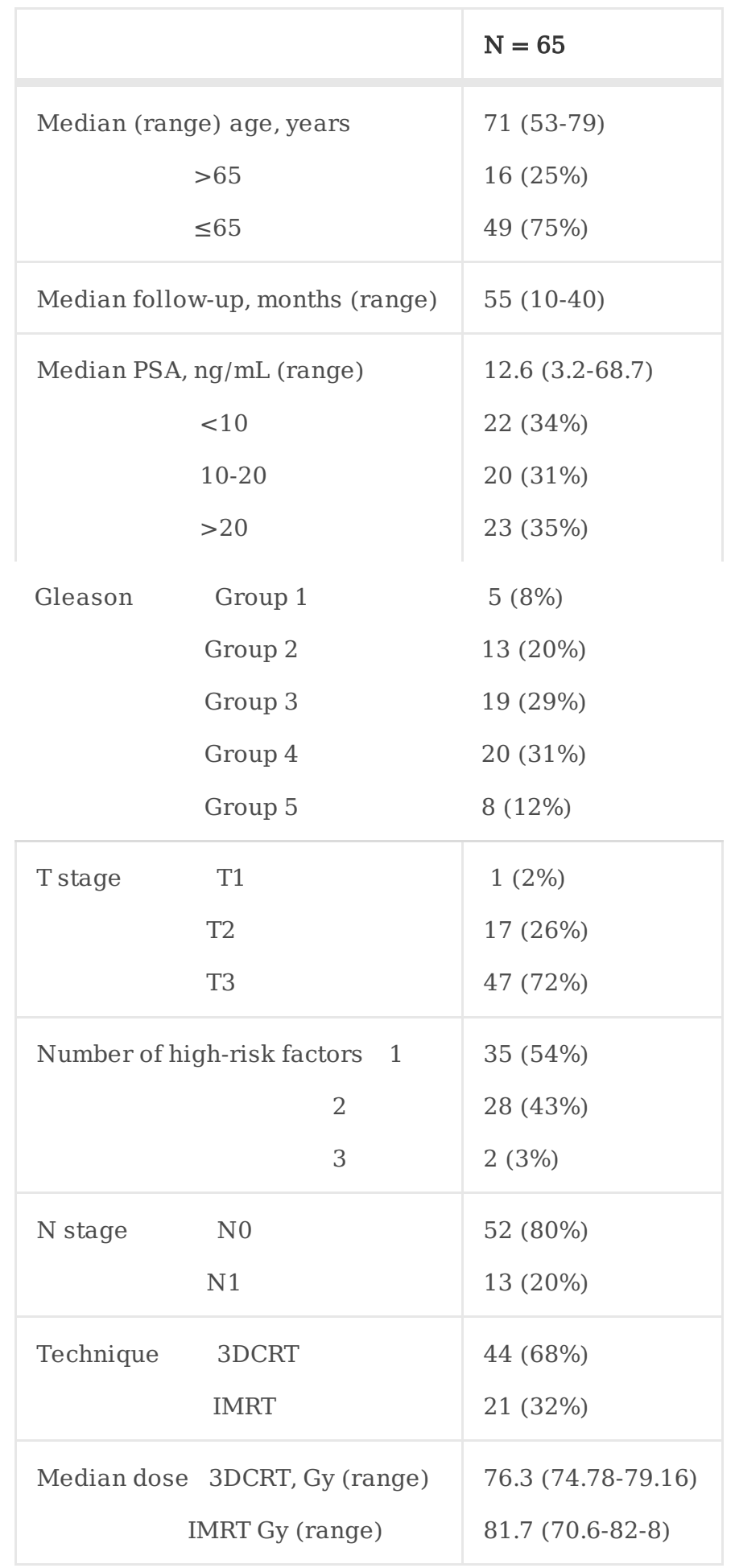

PSA, prostate-specific antigen; 3DCRT, 3-dimensional conformal radiation therapy; IMRT, intensity-modulated radiation therapy.

Table 2. CTC counts before and after treatment 


\begin{tabular}{|c|c|c|}
\hline & CTC Timing & CTC Positivity/Determinations \\
\hline CTC1 & $\begin{array}{l}\geq 1 \text { cells } / 7.5 \mathrm{ml} \text { (\%) (range) } \\
\quad 0\end{array}$ & $\begin{array}{c}5 / 65(7.5 \%)(1-6) \\
60\end{array}$ \\
\hline СТC2 & $\begin{array}{l}\geq 1 \text { cells } / 7.5 \mathrm{ml} \text { (range) } \\
0 \\
\text { Not performed }\end{array}$ & $\begin{array}{c}\text { 8/62(12.9\%) (1-1) } \\
\text { New presentation in } 6 \\
54 \\
3\end{array}$ \\
\hline СТС3 & $\begin{array}{l}\geq 1 \text { cells } / 7.5 \mathrm{ml} \text { (range) } \\
0 \\
\text { Not performed }\end{array}$ & $\begin{array}{c}11 / 59(18.6 \%)(1-136) \\
\text { New presentation in } 10 \\
48 \\
6\end{array}$ \\
\hline CTC4 & $\begin{array}{l}\geq 1 \text { cells /7.5 ml (range) } \\
0\end{array}$ & $\begin{array}{c}1 / 13(7.6 \%)(1) \\
\text { No new: persistence from СТC3 } 12\end{array}$ \\
\hline
\end{tabular}

CTC 1: Baseline; CTC 2: After neoadjuvant androgen deprivation therapy and before radiotherapy; CTC 3: After radiotherapy; CTC 4: 6-12 months after radiotherapy in patients with new positivity at CTC 2 or CTC 3.

Table 3. CTC positivity and association with prognostic factors 


\section{CTC1+ CTC2+}

\begin{tabular}{|c|c|c|c|c|c|}
\hline \multicolumn{2}{|c|}{ Age, $y \leq 65$} & 1 & 2 & 2 & 0 \\
\hline \multirow{2}{*}{\multicolumn{2}{|c|}{$\mathrm{p}$ value }} & 4 & 6 & 9 & 1 \\
\hline & & 1.000 & 1.000 & 0.712 & 1.000 \\
\hline \multirow[t]{4}{*}{ PSA } & $<10 \mathrm{ng} / \mathrm{mL}$ & 2 & 1 & 4 & 1 \\
\hline & $10-20 \mathrm{ng} / \mathrm{mL}$ & 2 & 5 & 4 & 0 \\
\hline & $>20 \mathrm{ng} / \mathrm{mL}$ & 1 & 2 & 2 & 0 \\
\hline & $\mathrm{p}$ value & 0.852 & 0.128 & 0.711 & 1.000 \\
\hline Gleason & $<8$ & 3 & 7 & 5 & 1 \\
\hline \multirow[t]{2}{*}{ sum } & $\geq 8$ & 2 & 1 & 6 & 0 \\
\hline & p value & 1.000 & 0.128 & 0.502 & 1.000 \\
\hline \multirow[t]{3}{*}{ T Stage } & $<\mathrm{T} 3$ & 0 & 1 & 6 & 0 \\
\hline & $\geq \mathrm{T} 3$ & 5 & 7 & 5 & 1 \\
\hline & $\mathrm{p}$ value & 0.312 & 0.668 & 0.062 & 1.000 \\
\hline \multirow[t]{3}{*}{ N Stage } & 0 & 5 & 7 & 7 & \\
\hline & 1 & 0 & 1 & 4 & 1 \\
\hline & $\mathrm{p}$ value & 0.574 & 1.000 & 0.053 & - \\
\hline
\end{tabular}

Secondary tumors

$\begin{array}{lllll}\text { Yes } & 3 & 6 & 9 & 0 \\ \text { No } & 2 & 2 & 2 & 1 \\ \text { p value } & 0.621 & 1.000 & 0.484 & 0.231\end{array}$

PSA: prostate-specific antigen.

\section{Figures}




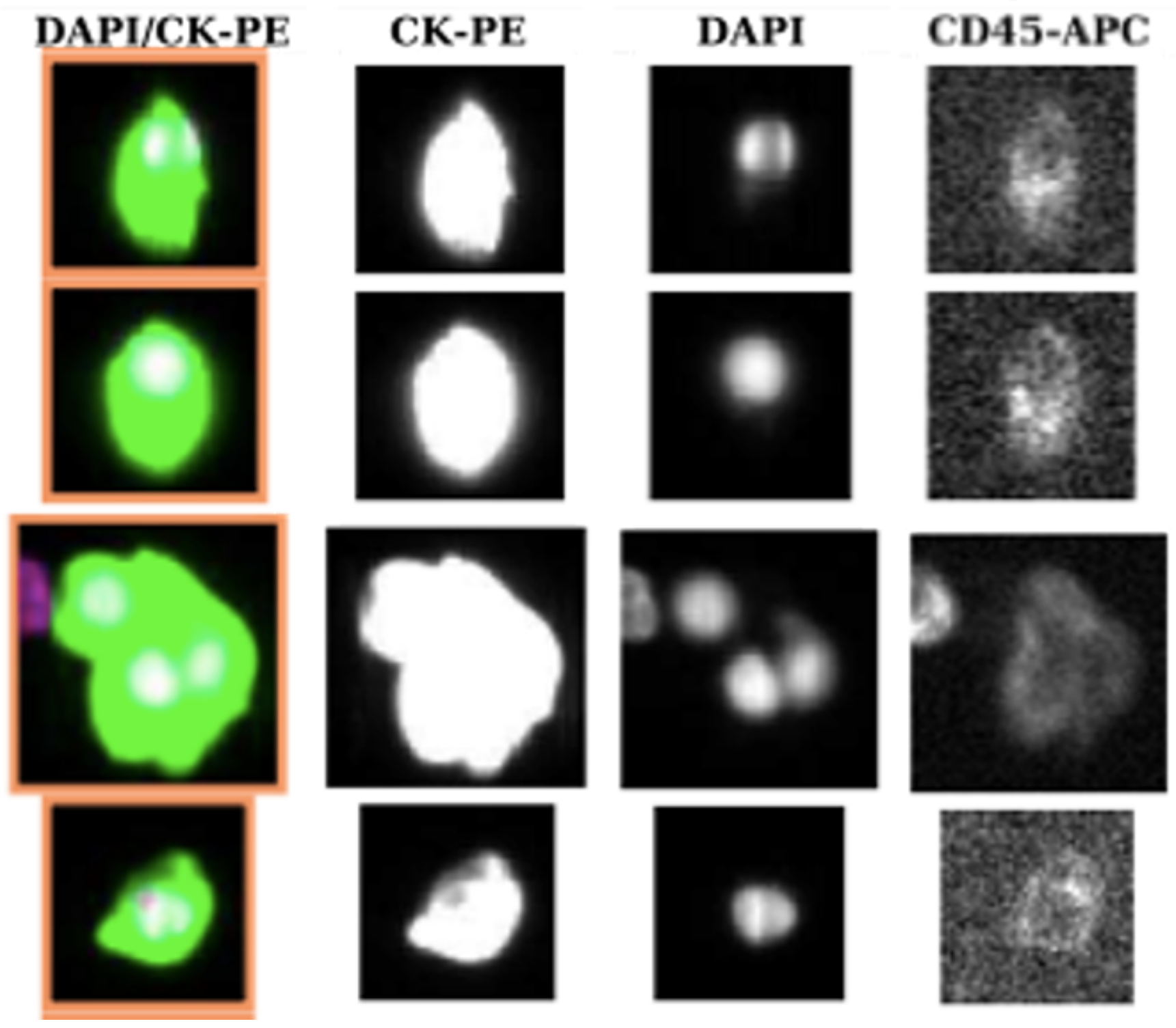

Figure 1

Images of CTCs obtained from a patient with prostate cancer using the CELLSEARCH system. Only round-oval, DAPI+, CD45-, and CK+ cells were considered CTCs. 


\section{CTC detection rate}

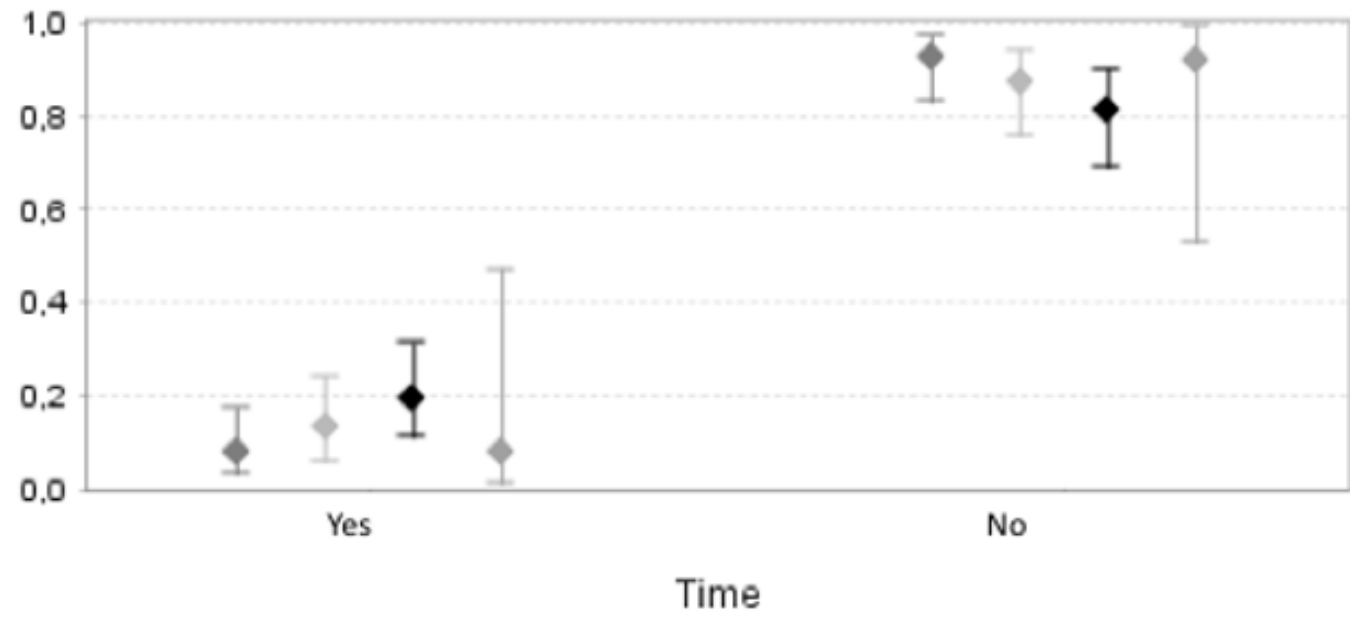

\section{$1=2 \square 3=4$}

1. Baseline

2. Post-neoadjuvant ADT - pre-RT

3. Post-RT - Preadjuvant ADT

4. 6-12 months following RT

\section{Figure 2}

CTCs detection rate at 4 timepoints: 1) baseline; 2) after neoadjuvant androgen deprivation therapy; 3) at the end of radiotherapy; and 4) 6-12 months after the end of radiotherapy in those patients with 0 CTCs in the first determination and a change to positive CTCs in the following determinations. CTC, circulating tumor cell; ADT, androgen deprivation therapy. 